\title{
Determination of Hydrologic Parameters of Fractured Rock Mass Based on Regional Groundwater Level Data in the Lake Karachai Area
}

\author{
E.G. Drozhko, Yu. G. Mokrov, and Yu. V. Glagolenko \\ Mayak Production Association \\ Ozersk Chelyabinsk Region, Russia \\ L.M. Samsonova \\ Production State Association Hydrospetzgeologiya \\ Moscow, Russia
}

September 1996

\author{
Russian American Center for Contaminant Transport Studies \\ Earth Sciences Division \\ Ernest Orlando Lawrence Berkeley National Laboratory \\ Berkeley, California 94720
}




\section{DISCLAIMER}

This report was prepared as an account of work sponsored by an agency of the United States Government. Neither the United States Government nor any agency thereof, nor any of their employees, make any warranty, express or implied, or assumes any legal liability or responsibility for the accuracy, completeness, or usefulness of any information, apparatus, product, or process disclosed, or represents that its use would not infringe privately owned rights. Reference herein to any specific commercial product, process, or service by trade name, trademark, manufacturer, or otherwise does not necessarily constitute or imply its endorsement, recommendation, or favoring by the United States Government or any agency thereof. The views and opinions of authors expressed herein do not necessarily state or reflect those of the United States Government or any agency thereof. 


\section{DISCLAIMER}

Portions of this document may be illegible in electronic image products. Images are produced from the best available original document. 


\begin{abstract}
Regional data of groundwater levels for wells in the Lake Karachai area are presented. A method to analyze these data is proposed for the evaluation of hydrological parameters of fractured rocks in this area. The calculated parameters are used to obtain volume losses as a result of filtration into the bed of Lake Karachai, which are then compared with direct data.
\end{abstract}





\section{Introduction}

Lake Karachai has been used by the PA "Mayak" as a radioactive waste storage since October, 1951. As the result of such use, a large volume of contaminated industrial liquids from the lake penetrated into the groundwater of the surrounding area. The lake lies in the area between Rivers Techa and Mishelyak, which are supplied by the surface flows and underground discharge. The form of the contaminated flow from the lake depends on hydrologic properties and on the groundwater flow field in the rock massif. An examination of the actual conditions of the flow regime and mass balance between Lake Karachai, and the groundwater as related to filtration flows of groundwater, makes a strong case for the development of unconventional methods in the estimation of hydrologic parameters of rock mass and filtration loss volumes from Lake Karachai.

\section{Determination of Hydrologic Parameters Based on Regional Groundwater Level Data}

The most significant parameters governing groundwater flow in the fractured rock massif are the permeability $\left(\mathrm{K}_{\mathrm{f}}\right)$, porosity $\left(\mathrm{n}_{0}\right)$, and transmissivity $(\mathrm{T})$. These parameters could be determined in two ways: first, by designing a simple calculating scheme and using it for data processing, and second, by evaluating data from regional study, followed by data processing. Generally, the processing of the results obtained through regional study is very complicated and normally run through various trial-and-error methods. At the same time, the mathematical relationship for homogeneous media is not always acceptable for inhomogeneous media such as fractured rock mass, particularly in cases where the pressure depression area is comparable to the geometric scale, characterizing the inhomogeneity of the medium under investigation. Therefore, from this point of view, the use of regional study integrating medium characteristics in the investigated area is preferable to the first scheme, because it avoids some of the uncertainties and discrepancies in the application of filtration equations for fractured rock massif. 
Lake Karachai lies at an elevation higher than the elevations of nearby ponds and rivers. Figure 1 shows a map of Lake Karachai and the investigation wells. The lake bed is porphyrite that is extensively fractured and overlapped by clay and loam, with a thickness of about $2 \mathrm{~m}$. About $4 \%$ of the lake area is overlapped by a plane of clay with a thickness of only $0.7 \mathrm{~m}$, resulting in a good hydraulic connection between the lake and the underlying groundwater. An analysis of the groundwater regime has revealed a number of main regime generating factors, which can be categorized into some genetic groups: geologic, climatic, biosoil, hydrologic, and a group of artificial factors. A phenomenological approach was employed for analyzing a groundwater regime involving the representation of the listed factors by generalizing parameters, followed by their analysis based on the solution of the equation for unsteady filtration. After the analysis of hydrohypsographical curves in the investigated area (see Figures 2-7), it was noted that the possibility exists for using a model of groundwater plane flow in the direction of their discharging zones. In such a case, the unsteady filtration regime of groundwater could be described by a one-dimensional equation of the following form (in approximation according to Verigin):

$$
\frac{\partial^{2} h^{2}(x, \tau)}{\partial_{x}^{2}}+\frac{2 W(x, \tau)}{K_{F}}=\frac{1}{a} \cdot \frac{\partial h^{2}(x, \tau)}{\partial \tau}
$$

where

$h=$ height of groundwater free surface relative to the horizontal impermeable bed, $\mathrm{m}$; $h_{s}=$ the same height averaged by Boussnesq equation linearization;

$K_{F}=$ permeability values, $\mathrm{m} /$ day;

$W=$ infiltration rate, $\mathrm{m} /$ day;

$\tau=$ time, days; and

$$
a=\frac{k_{F} h_{S}}{\mu_{S}} ; \quad h_{S}=\frac{1}{2} \cdot\left(h_{\max }+h_{\min }\right) .
$$


The storage $\mu$ can be considered equal to water take-up and release, because the deformation capacity in rock mass could not be taken into account. Let us supplement Equation (1) with boundary and initial conditions. For the boundary conditions, let us take the condition of the first kind, namely, the temporally constant value of groundwater level at the boundary of the investigated area, in particular at south sector:

$$
h(0, \tau)=h_{k} ; \quad h\left(L_{S}, \tau\right)=h_{M},
$$

where $h_{k}=$ Lake Karachai level relative to the watertight bed;

$h_{M}=$ River Mishelyak level relative to the watertight bed;

$L_{S}=$ distance between Lake Karachai and River Mishelyak.

Let us assume similar conditions for the north sector. As the initial condition, let us take the depression function of groundwater level, $h_{0}(x)$, meeting the boundary conditions (2) and the Equation (3):

$$
\frac{\partial^{2} h_{0}^{2}(x, \tau)}{\partial x^{2}}=0
$$

The function $h_{0}(x)$ is a depression of groundwater level under the given boundary conditions and with the absence of infiltration feeding.

Using the relationship (4)

$$
h^{2}(x, \tau)=h_{0}^{2}(x)+h_{1}^{2}(x, \tau)
$$

in Equation (1), we obtain

$$
\left\{\begin{array}{c}
\frac{\partial^{2} h^{2}(x, \tau)}{\partial x^{2}}+\frac{2 W(x, \tau)}{K_{F}}=\frac{1}{a} \bullet \frac{\partial h^{2}(x, \tau)}{\partial \tau} \\
h_{1}(0, \tau)=h_{1}\left(L_{S}, \tau\right)=0 \\
h_{1}(x, 0)=0
\end{array},\right.
$$


and

$$
\frac{\partial^{2} h_{0}^{2}(x)}{\partial x^{2}}=0 \quad ; \quad h_{0}(0)=h_{k} \quad ; \quad h_{0}\left(L_{S}\right)=h_{M}
$$

The solution of the initial problem is shown as a superposition of two independent solutions. Equation (6) describes a stationary depression curve established in the area without infiltration sources. Equation (5) describes the influence of infiltration on the groundwater level, modifying the Equation (6). The solution of Equation (6) for $h(x)$ takes the following form:

$$
h_{0}^{2}(x)=h_{k}^{2} \cdot\left(1-\frac{x}{L_{S}}\right)+h_{M}^{2} \cdot \frac{x}{L_{S}}
$$

Considering that the velocity of groundwater infiltration is constant for the whole problem area and changing the problem area in (5) from $0 \leq x \leq 1$ to $-L_{S} / 2 \leq x \leq L_{S} / 2$, we get the following solution for $h_{1}^{2}(x, t)$ :

$$
h_{1}^{2}(x, \tau)=\frac{8 a}{\pi k_{F}} \cdot \sum_{n=0}^{\infty} \frac{(-1)^{n}}{2 n+1} \cdot \cos \left(\frac{(2 n+1) \pi x}{L_{S}}\right) \cdot \int_{0}^{\tau}\left[W\left(\tau^{\prime}\right) e^{-\frac{4 \pi^{2} a(2 n+1)^{2}}{L_{S}^{2}}\left(\tau-\tau^{\prime}\right)}\right] d \tau^{\prime}
$$

If $W(\tau)=W_{0} / \tau=$ const

$$
h_{1}(x)=\frac{W_{0} L_{S}^{2}}{4 \tau_{d} k_{F}}\left[1-\frac{4 x^{2}}{L_{S}^{2}}-\frac{32}{\pi^{3}} \sum_{n=0}^{\infty}\left(\frac{\left(-1^{n}\right.}{(2 n+1)^{3}} \cos \left(\frac{(2 n+1) \pi x}{L_{S}}\right) e^{-a(2 n+1)^{2} \pi^{2} \tau / L_{S}^{2}}\right)\right]
$$

Taking into account the features of infiltration sources in the problem area (the scheme is given in Figure 8, and data are given in Figure 9), let us represent $h^{2}(x, \tau)$ as

$$
h^{2}(x, \tau)=h_{2}^{0}(x)+h_{s}^{2}(x, \tau)+h_{i-1}^{2}(x, \tau)+h_{i}^{2}(x, \tau),
$$

where $h_{s}=$ defines the level change in spring season

$h_{i-1}=$ defines the level change from precipitation of the last year;

$h_{i}=$ defines the level change from precipitation of the current year. 


$$
\begin{aligned}
& h_{i-1}^{2}(x, \tau)=\left\{\begin{array}{cc}
\frac{W_{i-1} \varepsilon_{i-1}^{*} L_{S}^{2}}{4 \tau_{d} k_{F}}\left(1-\frac{4 x^{2}}{L_{S}^{2}}\right) & \tau \leq \tau_{2} \\
-\frac{W_{i-1} \varepsilon_{i-1}^{*} L_{S}^{2}}{4 \tau_{d} k_{F}}\left(1-\frac{4 x^{2}}{L_{S}^{2}}-F\left(x, \tau-\tau_{1}\right)\right) & \tau>\tau_{2}
\end{array} ;\right. \\
& h_{S}^{2}(x, \tau)=\left\{\begin{array}{cl}
\frac{W_{Z} \varepsilon L_{S}^{2}}{4 k_{F}\left(\tau_{2}-\tau_{1}\right)}\left(1-\frac{4 x^{2}}{L_{S}^{2}}-F\left(x, \tau-\tau_{1}\right)\right) & \tau_{1} \leq \tau \leq \tau_{2} \\
\frac{W_{Z} \varepsilon L_{S}^{2}}{4 k_{F}\left(\tau_{2}-\tau_{1}\right)}\left(-F\left(x, \tau-\tau_{1}\right)+F\left(x, \tau-\tau_{2}\right)\right) & \tau>\tau_{2}
\end{array} ;\right. \\
& h_{i}^{2}(x, \tau)=\frac{W_{i} \varepsilon_{i}^{*} L_{S}^{2}}{4 \tau_{d} k_{F}}\left(1-\frac{4 x^{2}}{L_{S}^{2}}-F\left(x, \tau-\tau_{1}\right)\right) ; \tau>\tau_{2} \\
& F\left(x, \tau-\tau_{1}\right)=\frac{32}{\pi^{3}} \sum_{n=0}^{\infty} \frac{(-1)^{n}}{(2 n+1)^{3}} \cos \frac{(2 n+1) \pi x}{L_{S}} e^{-\frac{\left.4 \pi^{2} a(2 n+1)^{2}\right)}{L^{2}}\left(\tau-\tau_{i}\right)}
\end{aligned}
$$

where $\tau_{2}-\tau_{1}=$ snow-thawing period;

$\tau_{d}=$ rain feeding period $(\mathrm{t}=1$ year $)$

$\varepsilon_{i}^{*}=$ infiltration coefficient of precipitation;

$\varepsilon=$ infiltration coefficient during the snow thawing period for snow stocks $W_{z}$;

$W_{i-1}=$ annual precipitation in the previous year;

$W_{i}=$ annual precipitation in the current year.

\section{Determination of the Coefficient " $a$ "}

If we know the groundwater level $H_{0}$ before the spring elevation (at the moment $\tau_{1}$ ), then we can write for the wells in the central sector at this time as

$$
\left[H_{0}+\Delta h_{S}^{\max }\right]^{2}=H_{0}^{2}+\frac{W_{z} L^{2}}{4 k_{F}\left(\tau_{2}-\tau_{1}\right)}\left(1-\frac{4 x^{2}}{L_{S}^{2}}\right)\left(1-e^{-\frac{a \pi^{2}\left(\tau_{2}-\tau_{1}\right)}{L_{S}^{2}}}\right)
$$

For $\tau>\tau_{2}$ 
$\left[H_{0}+\Delta h_{S}(x, \tau)\right]^{2}=H_{0}^{2}\left(x_{i}\right)+\frac{W_{z} L^{2}}{4 k_{F}\left(\tau_{2}-\tau_{1}\right)}\left(1-\frac{4 x^{2}}{L^{2}}\right)\left(1-e^{-b\left(\tau_{2}-\tau_{1}\right)}\right) e^{-b\left(\tau_{2}-\tau_{1}\right)}$

where $b=\frac{a \pi^{2}}{L_{S}^{2}}$

After rearranging

$$
\left[H_{0)}+\Delta h_{S}\left(x_{i}, \tau\right)\right]^{2}-H_{0}^{2}\left(x_{i}\right)=\left(\left[H_{0}+\Delta h_{S}^{\max }\left(x_{i}, \tau\right)\right]^{2}-H_{0}^{2}\left(x_{i}\right)\right) e^{-b\left(\tau_{2}-\tau_{1}\right)}
$$

After normalizing and logarithm taking

$$
-\frac{a \pi^{2}\left(\tau_{2}-\tau_{1}\right)}{L^{2}}=\ln \left(\frac{\Delta h_{S}\left(x, \tau-\tau_{2}\right)}{\Delta h_{S}^{\max }} \cdot \frac{1+\frac{\Delta h_{S}\left(x, \tau-\tau_{2}\right)}{2 H_{0}}}{1+\frac{\Delta h_{S}^{\max }}{2 H_{0}}}\right) .
$$

With $\Delta h_{S}=\Delta h_{S}^{\max } / 2$ at the moment $\tau_{0}$, we get $a=\frac{0.633 L^{2}}{\pi\left(\tau_{0}-\tau_{2}\right)}=\frac{\lambda_{C M} L^{2}}{T_{1 / 2}}$, where $\lambda_{C M}=\frac{0.693}{T_{1 / 2}} ; T_{1 / 2}=\tau_{0}-\tau_{2}$.

Tables 1 and 2 show values of $a=\frac{k h}{\mu}$ in south and north directions from Lake

Karachai using the results of regional examinations of groundwater level, shown in Figures $10-17$. 
Table 1. Coefficients " $a$ " for Wells in South Direction.

\begin{tabular}{|c|c|c|c|c|c|c|}
\hline \multirow[t]{2}{*}{ Year } & \multicolumn{3}{|c|}{ Well 202/64 } & \multicolumn{3}{|c|}{ Well 10/68 } \\
\hline & $\begin{array}{c}\Delta h_{s} \max \\
\mathrm{m}\end{array}$ & $\begin{array}{l}\mathrm{T}_{1 / 2}, \\
\text { day }\end{array}$ & $\begin{array}{l}a^{*} 10^{-3} \\
\mathrm{~m}^{2} / \text { day }\end{array}$ & $\begin{array}{c}\Delta h_{s} \max \\
\mathrm{m}\end{array}$ & $\begin{array}{l}\mathrm{T}_{1 / 2}, \\
\text { day }\end{array}$ & $\begin{array}{l}a * 10^{-3} \\
\mathrm{~m}^{2} / \text { day }\end{array}$ \\
\hline 1972 & 1.6 & 65 & 6.8 & 1.0 & 45 & 9.8 \\
\hline 1973 & 1.0 & 45 & 9.8 & 1.1 & 50 & 8.8 \\
\hline 1974 & 1.2 & 50 & 8.8 & 1.0 & 50 & 8.3 \\
\hline 1975 & 0.25 & - & - & 0.2 & - & - \\
\hline 1976 & 0.4 & 45 & 9.8 & 0.5 & 40 & 11.0 \\
\hline 1977 & 1.1 & 65 & 6.8 & 1.5 & 55 & 8.8 \\
\hline 1978 & 1.5 & - & - & 1.6 & - & - \\
\hline 1979 & 2.1 & 70 & 6.3 & 2.0 & 55 & 8.8 \\
\hline 1980 & 1.5 & 50 & 8.8 & 1.5 & - & - \\
\hline 1981 & 2.4 & 45 & 9.8 & 1.5 & 70 & 6.3 \\
\hline 1982 & 0.7 & 40 & 11.0 & 0.9 & 35 & 12.6 \\
\hline
\end{tabular}

Table 2. Coefficients " $a$ " for Wells in North Direction.

\begin{tabular}{|c|c|c|c|c|c|c|}
\hline \multirow[t]{2}{*}{ Year } & \multicolumn{2}{|c|}{ Well $15 / 70$} & \multicolumn{2}{|c|}{ Well 36/70 } & \multicolumn{2}{|c|}{ Well 38/70 } \\
\hline & $\begin{array}{l}\mathrm{T}_{1 / 2}, \\
\text { day }\end{array}$ & $\begin{array}{c}a, \\
\mathrm{~m}^{2} / \text { day }\end{array}$ & $\begin{array}{l}\mathrm{T}_{1 / 2}, \\
\text { day }\end{array}$ & $\begin{array}{c}a, \\
\mathrm{~m}^{2} / \mathrm{day}\end{array}$ & $\begin{array}{l}\mathrm{T}_{1 / 2}, \\
\text { day }\end{array}$ & $\begin{array}{c}a, \\
\mathrm{~m}^{2} / \text { day }\end{array}$ \\
\hline 1972 & - & - & 55 & 2.6 & 30 & 4.8 \\
\hline 1973 & 75 & 1.9 & 70 & 2.0 & 60 & 2.4 \\
\hline 1974 & 60 & 2.4 & 70 & 2.0 & 40 & 3.6 \\
\hline 1975 & 50 & 2.8 & - & - & 60 & 2.4 \\
\hline 1976 & 60 & 2.4 & 45 & 3.2 & 70 & 3.0 \\
\hline 1977 & 65 & 2.2 & 60 & 2.4 & - & - \\
\hline 1978 & - & - & 55 & 2.6 & 70 & 2.0 \\
\hline 1979 & - & - & 65 & 2.2 & 70 & 2.0 \\
\hline 1980 & - & - & 55 & 1.9 & 50 & 2.8 \\
\hline
\end{tabular}

\section{Evaluation of the Averaged Transmissivity}

Although the conductivity characterizes the pressure fields, an openflow bed could be characterized by a value similar to conductivity notation by the linearization of unsteady filtration equation in the N.N. Verigin approximation. 
For the evaluation of this value, we use the data over the period when the infiltration in this area was absent from 1975 to 1977 . By using a depression curve, we shall get the following relationships for the filtration velocity from the Lake Karachai $v_{F}$ of the front width $I_{0}$ and the same coefficient both to the south and north directions.

$$
\begin{aligned}
& V_{F S}=\frac{l_{0} \Delta H_{S}}{L_{S}} \overline{k_{F S} H_{S S}}\left(1+\frac{L_{S}}{L_{N}} \cdot \frac{\Delta H_{N}}{\Delta H_{S}} \cdot \frac{a_{N}}{a_{S}}\right) ; \\
& L_{S}=1500 ; L_{N}=4500 ; \Delta H_{S}=H_{K}-H_{M}=6.5 m ; \\
& \Delta H_{N}=H_{K}-H_{T}=21 m ; H_{S S}=\frac{H_{K}+H_{M}}{2} ; H_{S N}=\frac{H_{K}+H_{T}}{2} .
\end{aligned}
$$

The maximum value of filtration velocity was observed in 1976-1977 and was about $950 \mathrm{~m}^{3} / \mathrm{d}$. We can calculate values $\overline{h_{S S} k_{F S}}$ and $\overline{h_{S N} k_{F N}}$ for this value of filtration velocity using (16). Then $T_{S}=\overline{h_{S S} k_{F S}}=40 \mathrm{~m}^{2} / d, T_{N}=\overline{h_{S N} k_{F N}}=110 \mathrm{~m}^{2} / d$.

We can evaluate the effective fracture porosity $\mu_{\mathrm{s}}$ by using the water balance results of Lake Karachai for the period 1976 to 1977 and the values for $\overline{k_{F} h_{S}}$ and $a$. The evaluation for the south and north directions shows similar values for $\mu_{\mathrm{s}}$ about 0.0044 . These values are in sufficiently good agreement with direct data, as well as with the results of special hydrogeologic explorations (Figure 18).

\section{Evaluation of Groundwater Infiltration Sources}

By using the approximation $H\left(x_{i}\right) k_{F} \approx \overline{h_{S S} k_{F S}}$ and $H_{0} \gg D h_{i}$, we get for the snowthawing period

$$
\varepsilon=\frac{8 h_{S} k_{F} \Delta h\left(x_{i}, \tau_{2}-\tau_{1}\right)}{W_{z} L^{2}\left[1-\frac{4 x_{i}^{2}}{L_{j}^{2}}-\frac{32}{\pi^{3}} \cos \left(\frac{\pi x_{i}}{L_{j}} \exp \left(-\lambda_{C M}\left(\tau_{2}-\tau_{1}\right)\right)\right)\right]}
$$


Table 3. Infiltration coefficients of precipitation for south direction in spring.

\begin{tabular}{|c|c|c|c|c|c|c|c|c|c|c|}
\hline \multirow[t]{2}{*}{ Year } & \multirow{2}{*}{$\begin{array}{c}\mathrm{W}_{\mathrm{z}} \\
\mathrm{mm}\end{array}$} & \multicolumn{3}{|c|}{ Well 202/64 } & \multicolumn{3}{|c|}{ Well 10/68 } & \multicolumn{3}{|c|}{ Well 3/68 } \\
\hline & & $\begin{array}{c}\tau_{2}-\tau_{1} \\
\text { day }\end{array}$ & $\begin{array}{c}\Delta \mathrm{h}_{\mathrm{m}}, \\
\mathrm{m}\end{array}$ & $\varepsilon$ & $\begin{array}{c}\tau, \\
\text { day }\end{array}$ & $\underset{\mathrm{m}}{\Delta \mathrm{h}_{\mathrm{m}},}$ & $\varepsilon$ & $\begin{array}{c}\tau, \\
\text { day }\end{array}$ & $\begin{array}{c}\Delta \mathrm{h}_{\mathrm{m}} \\
\mathrm{m}\end{array}$ & $\varepsilon$ \\
\hline 1972 & 96 & 30 & 1.6 & 0.06 & 50 & 1.2 & 0.102 & - & - & - \\
\hline 1973 & 112 & 40 & 0.8 & 0.049 & 20 & 1.2 & 0.069 & 20 & 0.8 & 0.07 \\
\hline 1974 & 104 & 45 & 1.2 & 0.082 & 30 & 1.0 & 0.069 & 70 & 0.7 & 0.09 \\
\hline 1975 & 80 & 55 & 0.4 & 0.039 & 60 & 0.5 & 0.054 & 45 & 0.5 & 0.107 \\
\hline 1976 & 96 & 50 & 1.1 & 0.084 & 70 & 1.4 & 0.134 & 90 & 0.7 & 0.112 \\
\hline 1977 & 106 & 60 & 1.4 & 0.105 & 90 & 1.6 & 0.156 & 60 & 1.0 & 0.127 \\
\hline 1978 & 106 & 65 & 1.8 & 0.126 & 90 & 2.0 & 0.196 & 90 & 1.4 & 0.214 \\
\hline 1980 & 162 & 40 & 1.4 & 0.059 & 30 & 1.5 & 0.103 & 55 & 1.3 & 0.103 \\
\hline
\end{tabular}

For infiltration coefficient of precipitation

$$
\varepsilon^{*}=\frac{8 h_{i}\left(\overline{h_{S} k_{F}}\right) \tau_{d}}{L_{j}^{2}\left(1-\frac{4 x_{i}^{2}}{L_{j}^{2}}\right) W_{d}} .
$$

where $h_{1}=$ elevation relatively $h_{0}\left(x_{i}\right)$.

Table 4. Infiltration coefficients in the rain period.

\begin{tabular}{ccccccccc}
\hline Year & \multicolumn{2}{c}{ Well $202 / 64$} & & \multicolumn{2}{c}{ Well 10/68 } & & \multicolumn{2}{c}{ Well 3/68 } \\
\cline { 2 - 3 } \cline { 8 - 9 } \cline { 7 - 8 } & $\mathrm{h}_{\mathrm{i}}$ & $\varepsilon^{*}$ & & $\mathrm{~h}_{\mathrm{i}}$ & $\varepsilon^{*}$ & & $\mathrm{~h}_{\mathrm{i}}$ & $\varepsilon^{*}$ \\
\hline 1971 & 2.8 & 0.056 & & 3.0 & 0.067 & & 2.1 & 0.073 \\
1972 & 2.2 & 0.044 & & 2.1 & 0.047 & & 1.5 & 0.052 \\
1973 & 2.2 & 0.044 & & 2.2 & 0.049 & & 1.6 & 0.056 \\
1974 & 1.4 & 0.028 & & 1.1 & 0.024 & & 0.8 & 0.023 \\
1975 & 0.4 & 0.028 & & 0.0 & 0.0 & & 0.0 & 0.0 \\
1976 & 0.0 & 0.0 & & 0.0 & 0.0 & & 0.0 & 0.0 \\
1977 & 0.0 & 0.0 & & 0.0 & 0.0 & & 0.0 & 0.0 \\
1978 & 1.0 & 0.020 & & 1.3 & 0.029 & & 1.1 & 0.038 \\
1979 & 1.4 & 0.028 & & 1.5 & 0.033 & & 1.1 & 0.038 \\
1980 & 1.5 & 0.030 & & 1.6 & 0.036 & & 1.4 & 0.049 \\
1981 & 1.1 & 0.022 & & 1.1 & 0.027 & & 1.9 & 0.066 \\
1982 & 0.7 & 0.014 & & 0.7 & 0.016 & & 1.7 & 0.059 \\
1983 & 1.7 & 0.034 & & 1.4 & 0.031 & & 2.6 & 0.090 \\
\hline
\end{tabular}




\section{Water Balance}

The solution of volume $G_{\varphi}$ entering the groundwater flow could be defined by the relationship

$$
G \varphi=\left.\frac{k_{F} l_{0}}{2} \cdot \int_{0}^{\tau} \frac{\partial h^{2}\left(x, \tau^{\prime}\right)}{\partial \tau^{\prime}}\right|_{x=L / 2} d \tau^{\prime}
$$

For the flow towards south,

$$
\begin{aligned}
G \varphi_{S} & =\left(k_{F} h_{S}\right)_{S}\left[l_{0} \frac{H_{K}-H_{M}}{L_{S}} \tau_{2}-\frac{4 h_{i-1} \tau_{2} l_{0}}{L_{S}\left(1-\frac{4 x_{i}^{2}}{L_{1}^{2}}\right)} \cdot\left(1+\frac{L_{S}^{2}}{12 \tau_{d} a_{S}}\right)-\right. \\
& -\frac{4 h_{m i} l_{0}\left(\tau_{2}-\tau_{1}\right)}{L_{S}\left(1-\frac{4 x_{i}^{2}}{L_{S}^{2}}\right) e^{-\lambda} \lambda_{C M}\left(\tau_{2}-\tau_{1}\right)}-\frac{4 h_{i}\left(\tau_{d}-\tau_{1}\right)}{L_{S}\left(1-\frac{4 x_{i}^{2}}{L_{S}^{2}}\right)}\left(1-\frac{L_{S}^{2}}{12 \tau_{d} a_{S}}\right)
\end{aligned}
$$

where $h_{i-1}=$ the elevation of groundwater level in $x_{i}$ relative to the level $h_{0}\left(x_{i}\right)$ in winter of current year;

$h_{i}=$ the same in autumn;

$h_{m i}=$ the same in winter.

We can get a similar relationship for the north flow or we can use Equation (15). 
Table 5. Solution Volume Entering the Groundwater from the Lake Well 202/64.

\begin{tabular}{|c|c|c|c|c|c|c|}
\hline Year & $\mathrm{h}_{1}$ & $\mathrm{~h}_{\mathrm{mi}}$ & $\tau_{1}$ & $\tau_{2}-\tau_{1}$ & $\begin{array}{c}v_{\text {eval }} 10^{3} \\
\mathrm{~m}^{3}\end{array}$ & $\begin{array}{c}v_{\text {fact }} 10^{3} \\
\mathrm{~m} 3\end{array}$ \\
\hline 1971 & 2.8 & 1.3 & 105 & 45 & 117 & 141 \\
\hline 1972 & 2.2 & 1.6 & 105 & 65 & 130 & 117 \\
\hline 1973 & 2.2 & 0.8 & 90 & 45 & 136 & 163 \\
\hline 1974 & 1.4 & 1.2 & 90 & 60 & 177 & 116 \\
\hline 1975 & 0.4 & 0.0 & 90 & 60 & 240 & 295 \\
\hline 1976 & 0.0 & 0.4 & 90 & 45 & 230 & 255 \\
\hline 1977 & 0.0 & 1.1 & 60 & 65 & 220 & 229 \\
\hline 1978 & 1.0 & 1.4 & 90 & 90 & 186 & 178 \\
\hline 1979 & 1.4 & 1.8 & 90 & 70 & 96 & 55 \\
\hline 1980 & 1.5 & 1.4 & 90 & 50 & 122 & 98 \\
\hline 1981 & 1.1 & 2.4 & 90 & 45 & 85 & 95 \\
\hline 1982 & 0.7 & 0.7 & 90 & 75 & 137 & 191 \\
\hline 1983 & 1.7 & 1.3 & 75 & 40 & 103 & 142 \\
\hline
\end{tabular}

Surface run-off from the individual watershed is taken to be zero, because the lake water flow is intercepted by dams.

\section{Summary}

The evaluation performed shows a sufficiently good agreement between the calculated hydrogeologic parameters based on our approach and the experimental results obtained by various methods (see Table 5). A good correspondence between the calculated and the balance values of filtration losses from the lake verifies this conclusion also.

\section{Acknowledgment}

This paper was prepared under the auspices of Russian-American Center for Contaminant Transport Studies at the Lawrence Berkeley National Laboratory. We appreciate the funding support from the Office of Energy Research, Engineering and Geosciences Division of the U.S. Department of Energy through Contract Number DEAC03-76SF00098. 
We thank Dr. J.S.Y. Wang and Dr. A. Mishra for their review, comments, and editorial improvements. We should like to express sincere gratitude to Dr. Chin-Fu Tsang for his support and encouragement. 


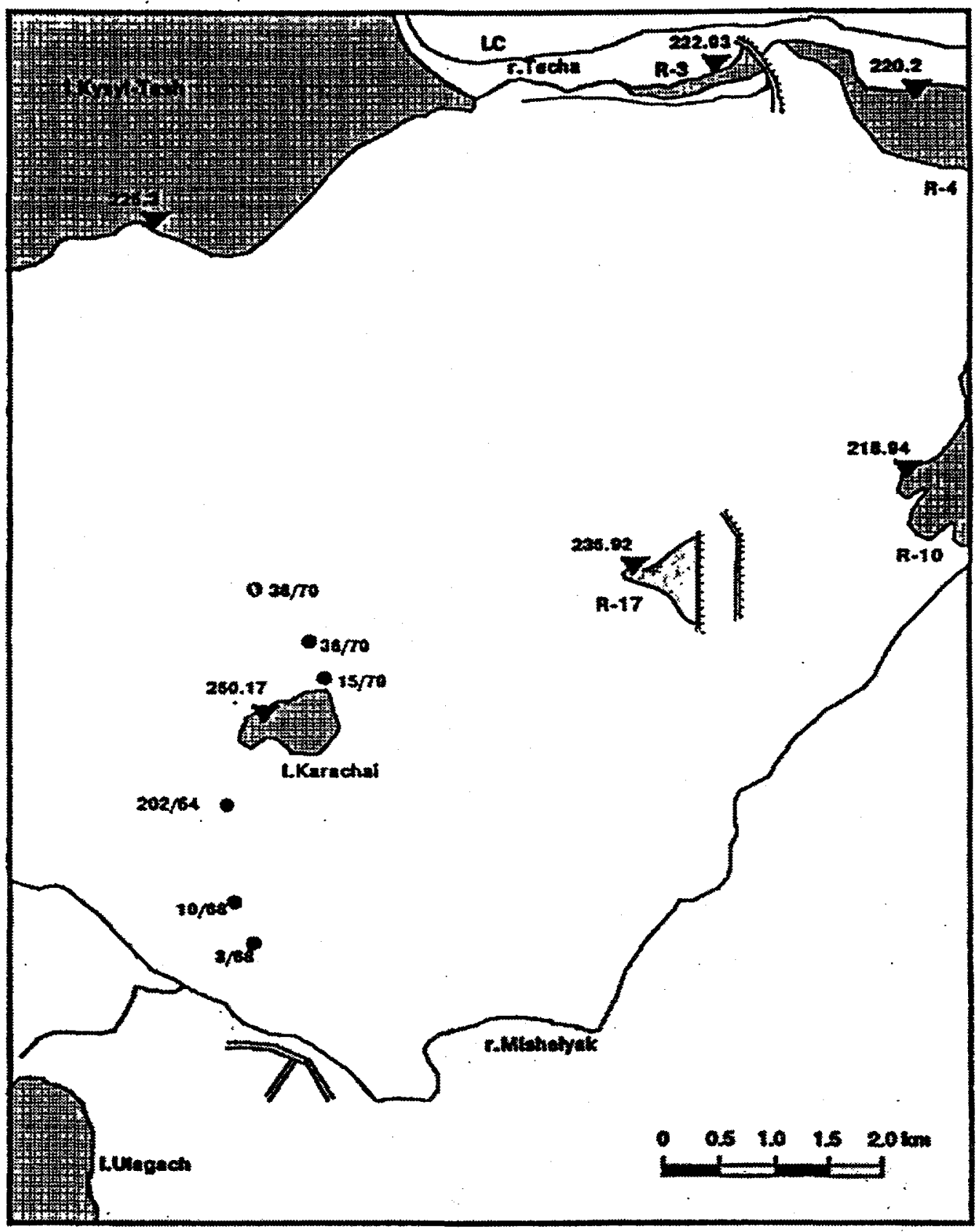

Figure 1. Scheme of investigation holes. 


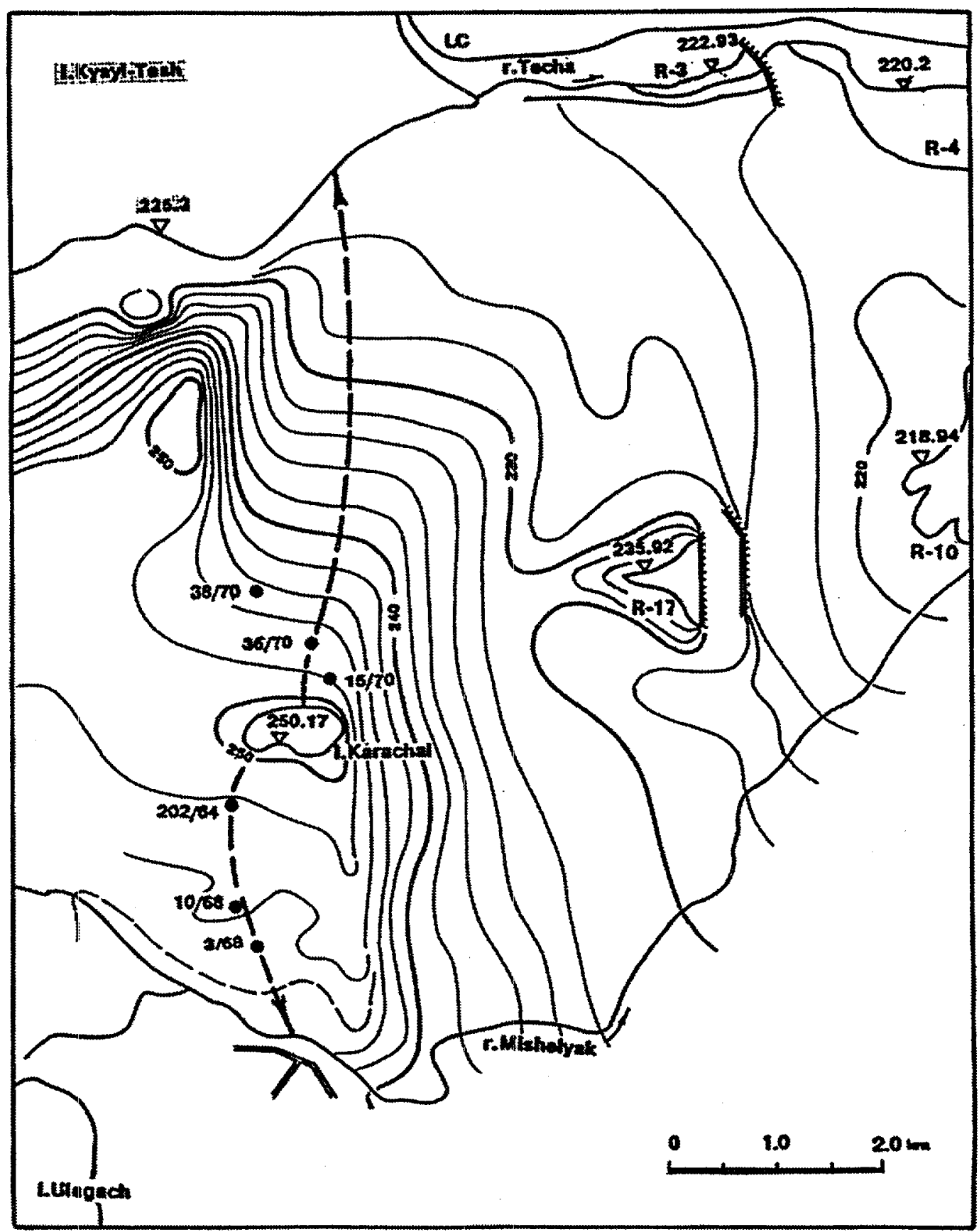

Figure 2. Hydrohypsographical curves of investigated area. 


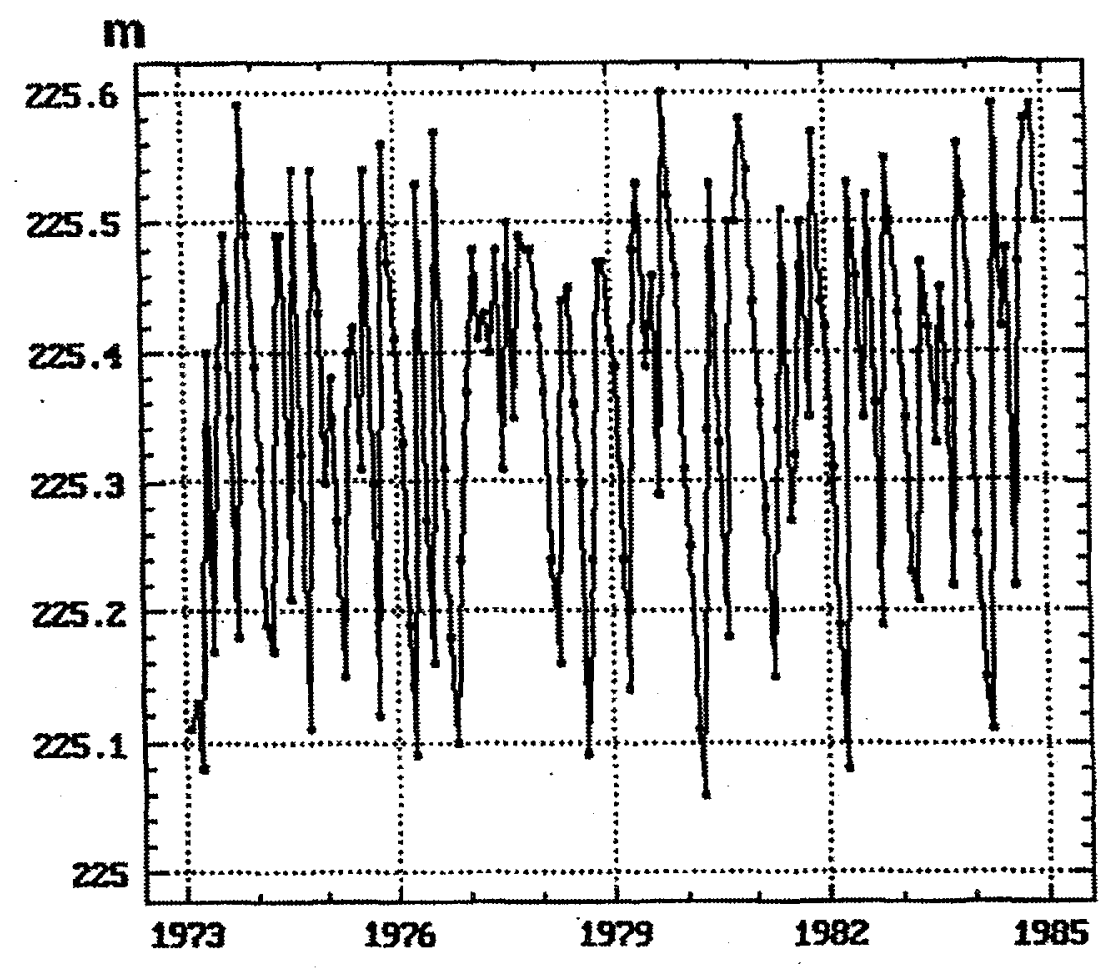

Figure 3. Water level at Lake Kyzyl-Tash (No. 2) in 1973-1985. 


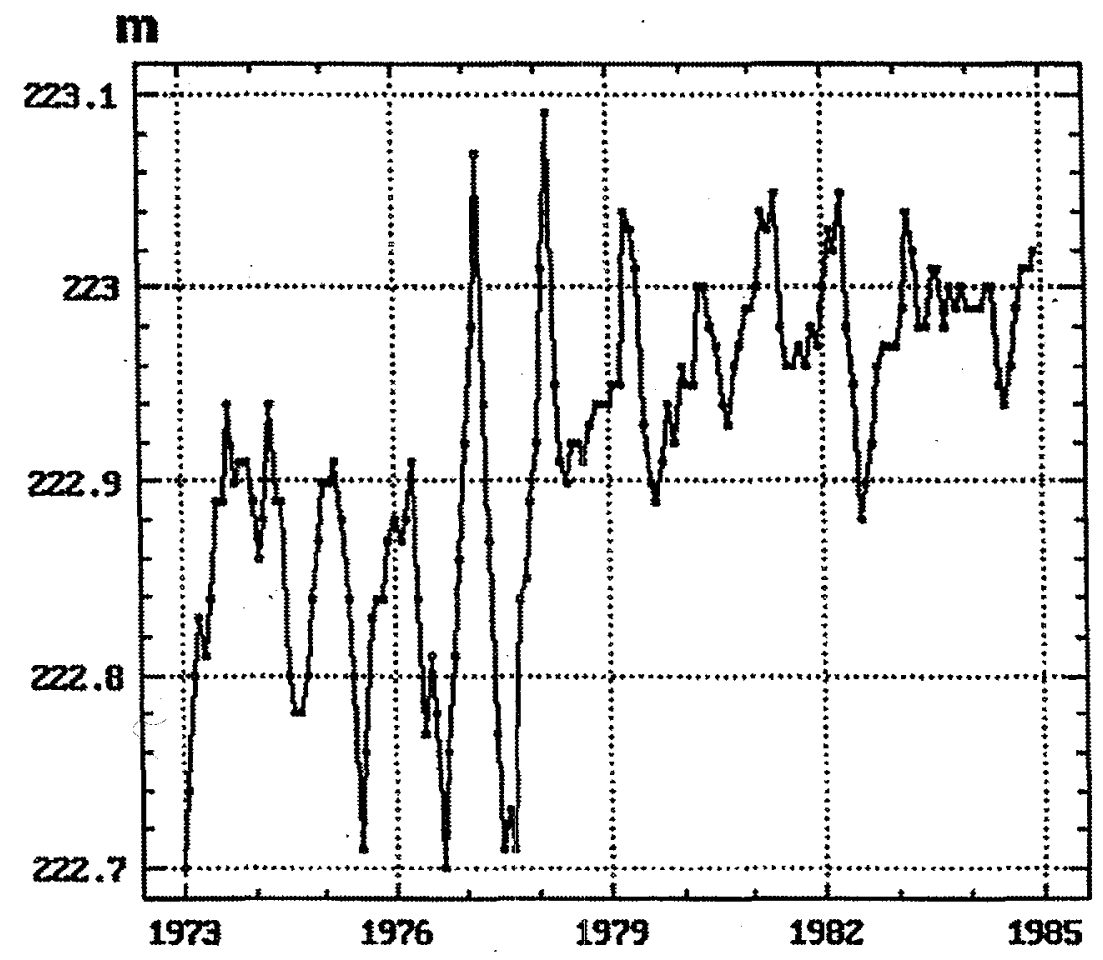

Figure 4. Water level in Lake No. 3 (r. Techa) in 1973-1985. 


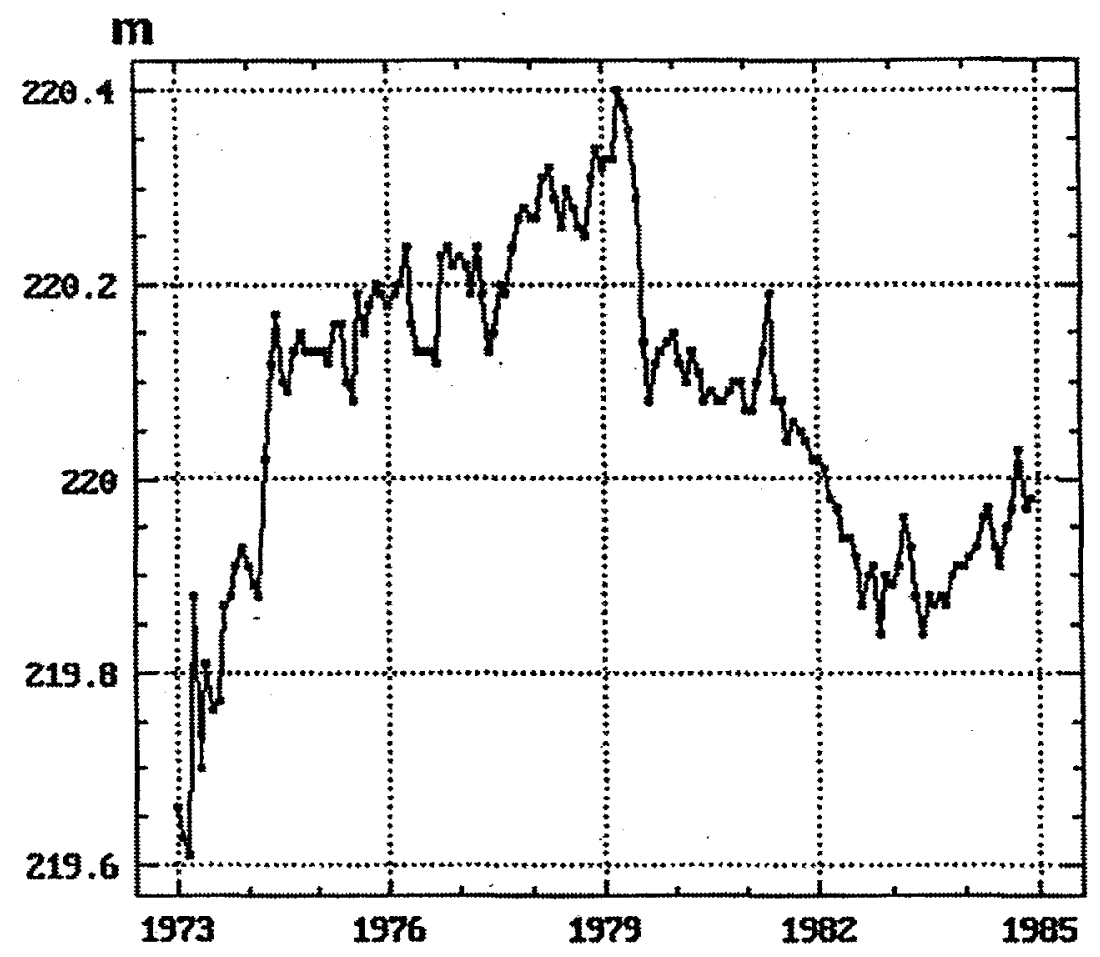

Figure 5. Water level in Lake No. 4 in 1973-1985. 


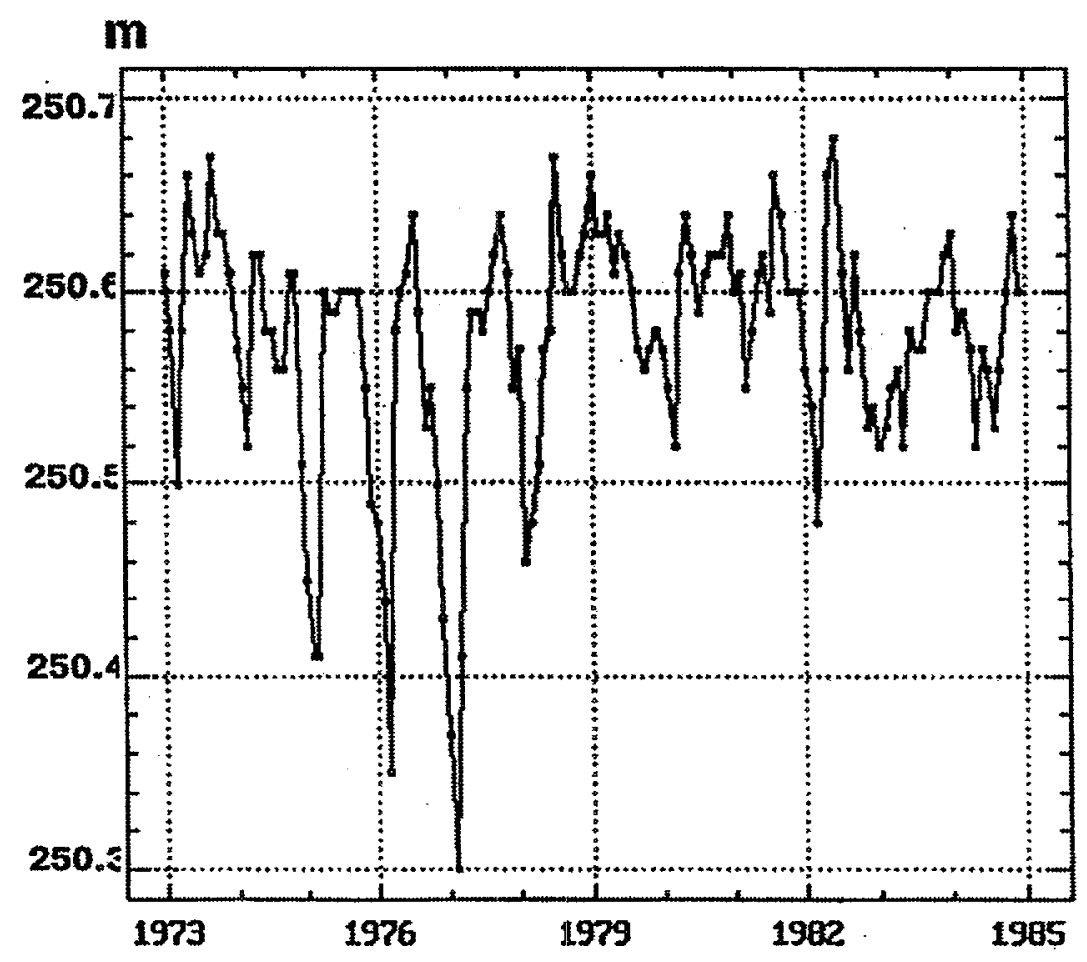

Figure 6. Water level in Lake Karachai in 1973-1985. 


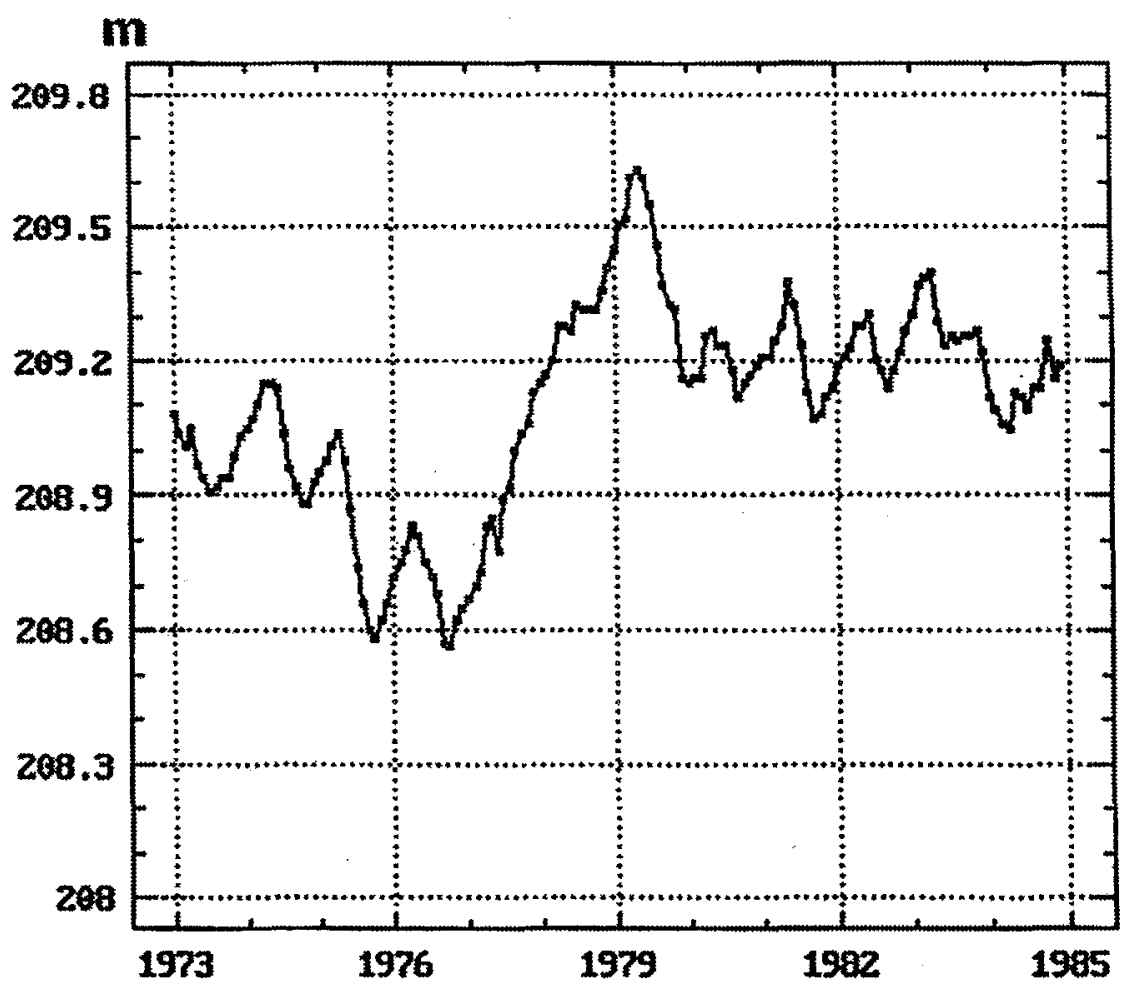

Figure 7. Water level in Lake No. 10 in 1973-1985. 


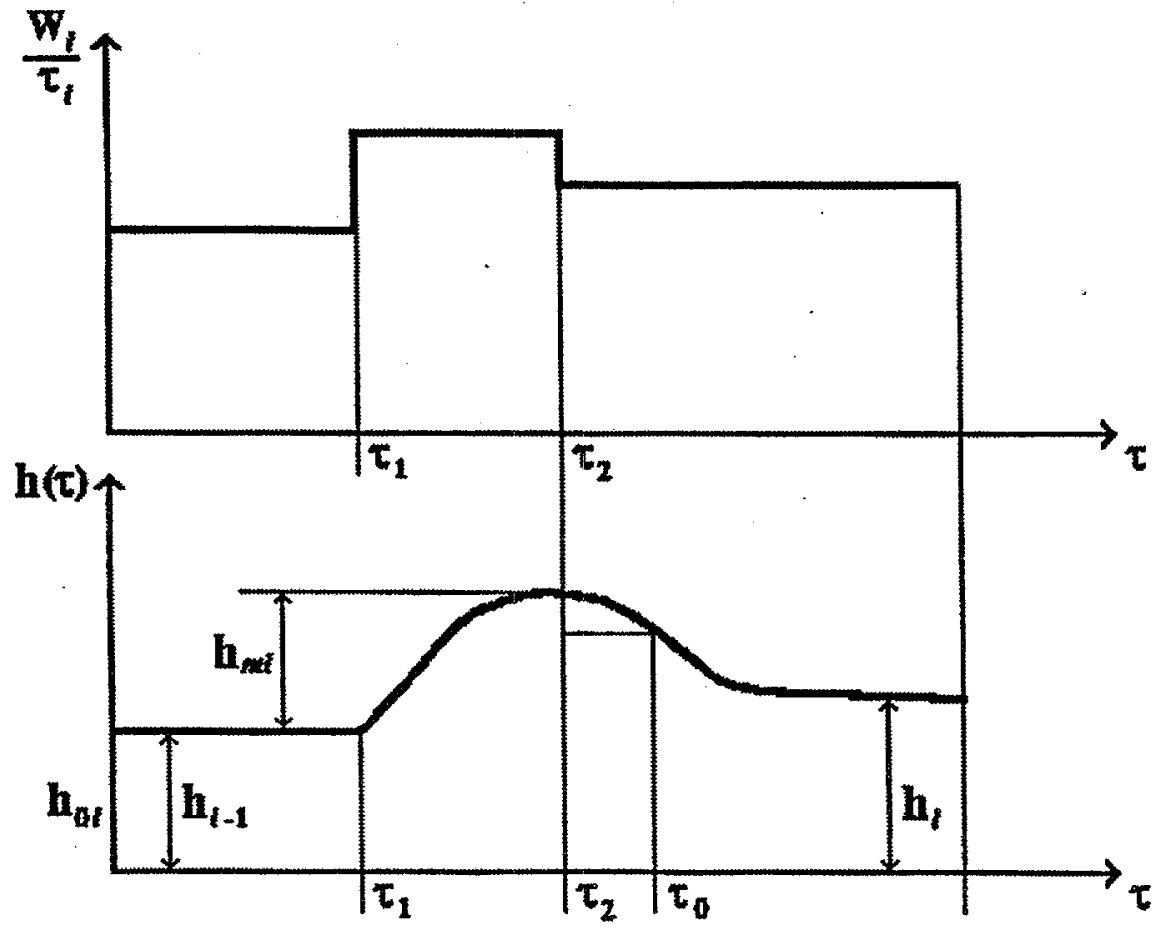

Figure 8. Scheme of infiltration feeding. 
Figure 9. Precipitation in 1970 to $1984, \mathrm{~mm}$.

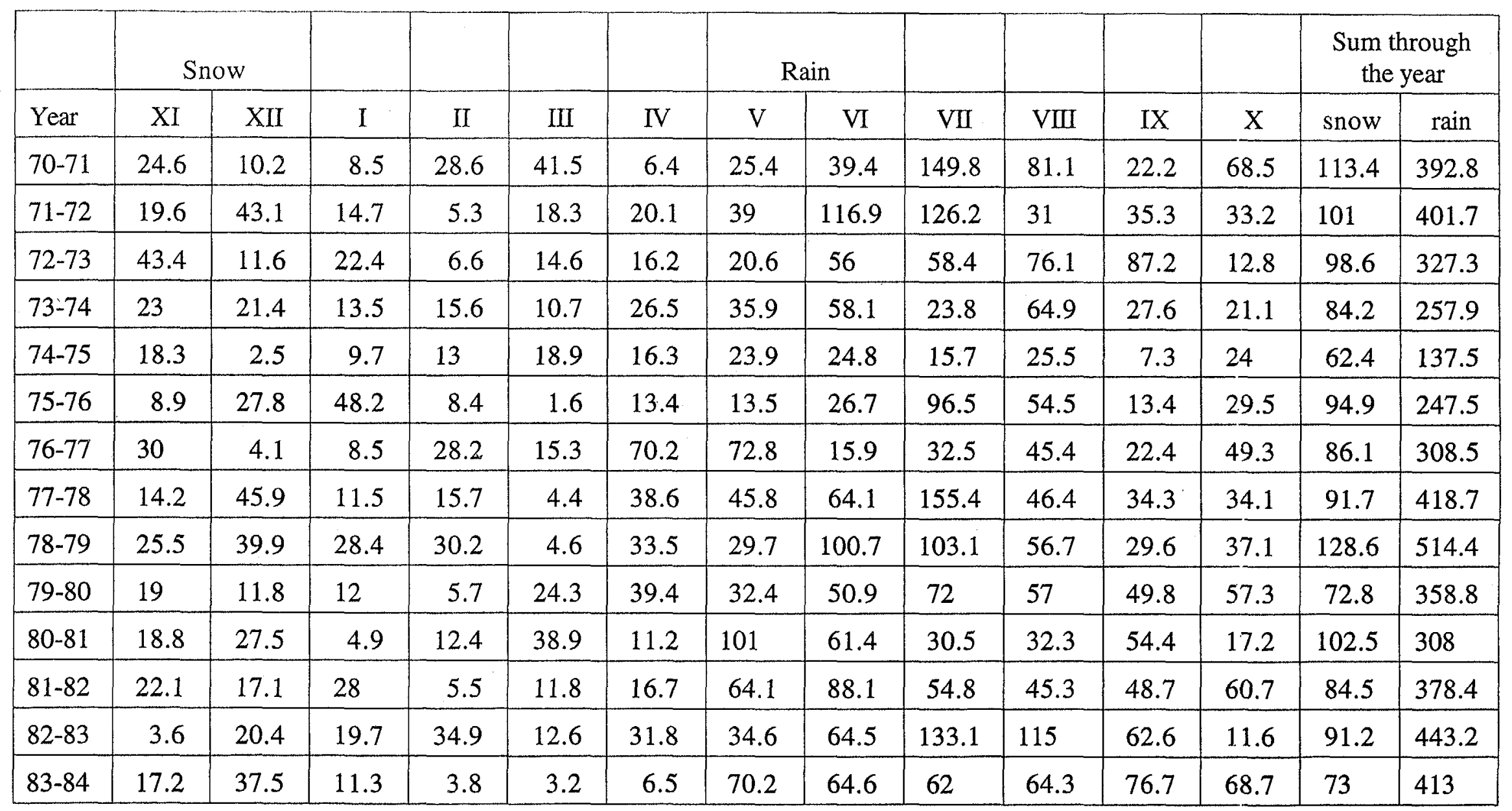




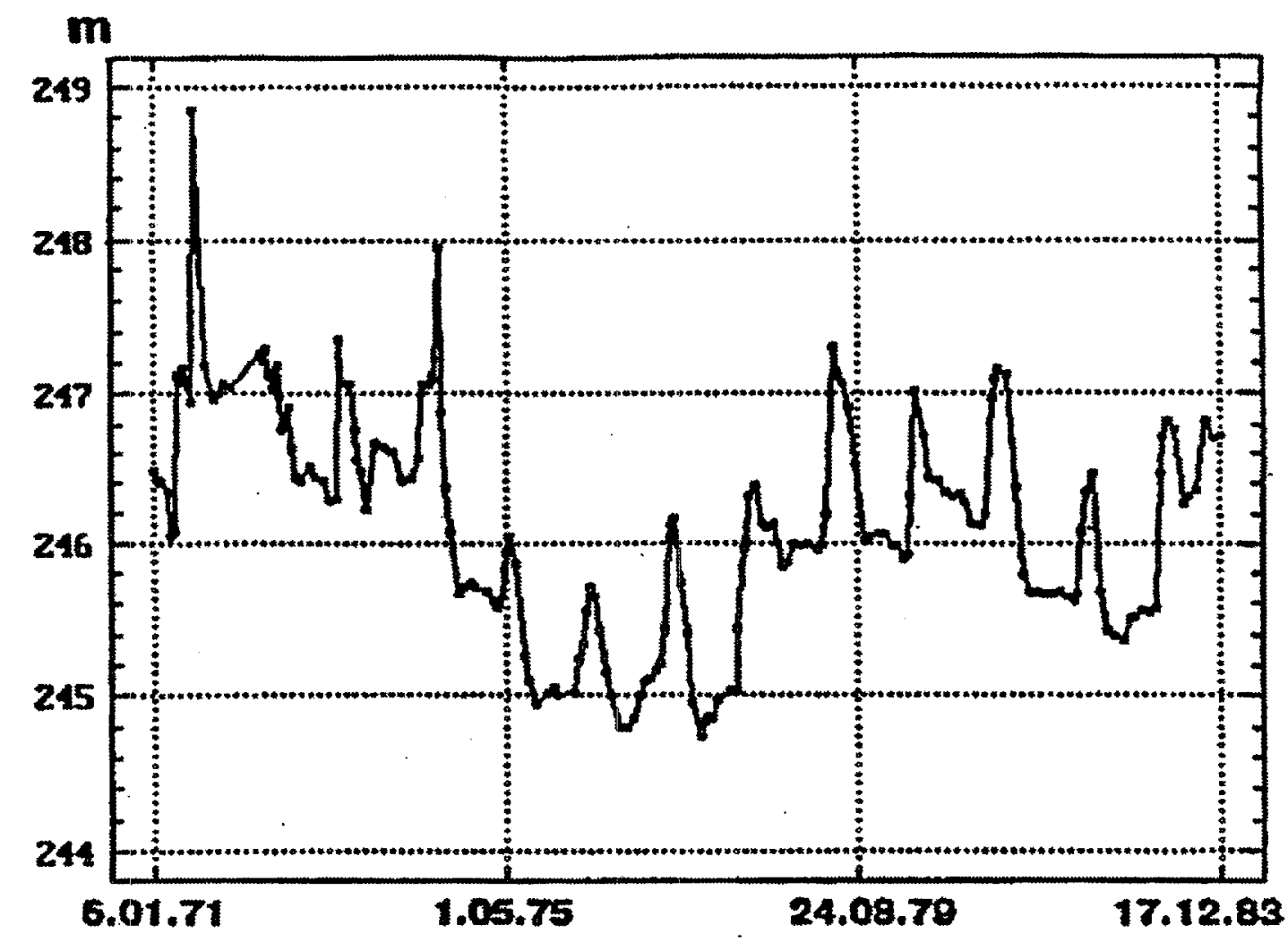

Figure 10. Water level in Well $3 / 68$ in 1971-1983. 


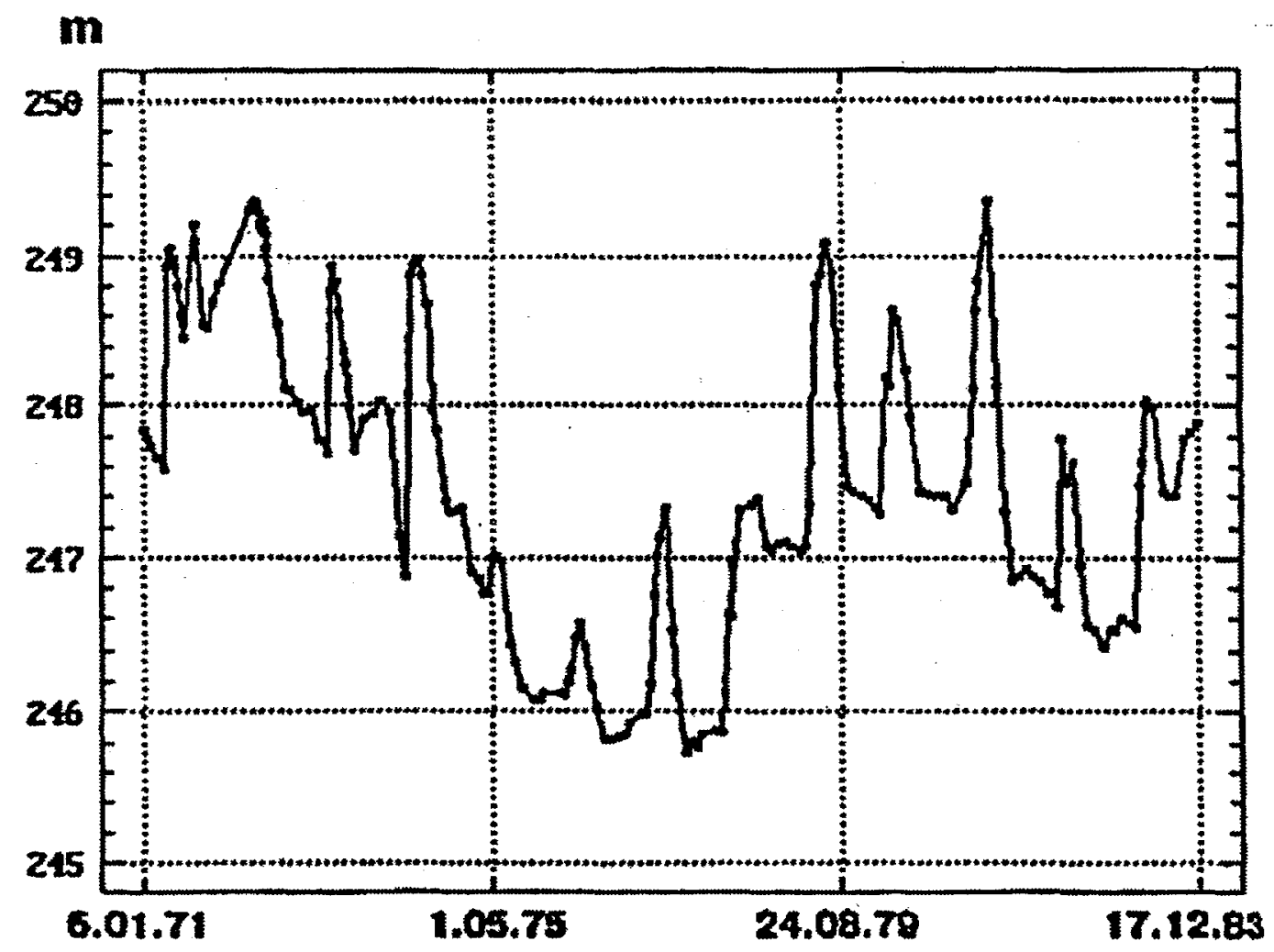

Figure 11. Water level in Well 10/68 in 1971-1983. 


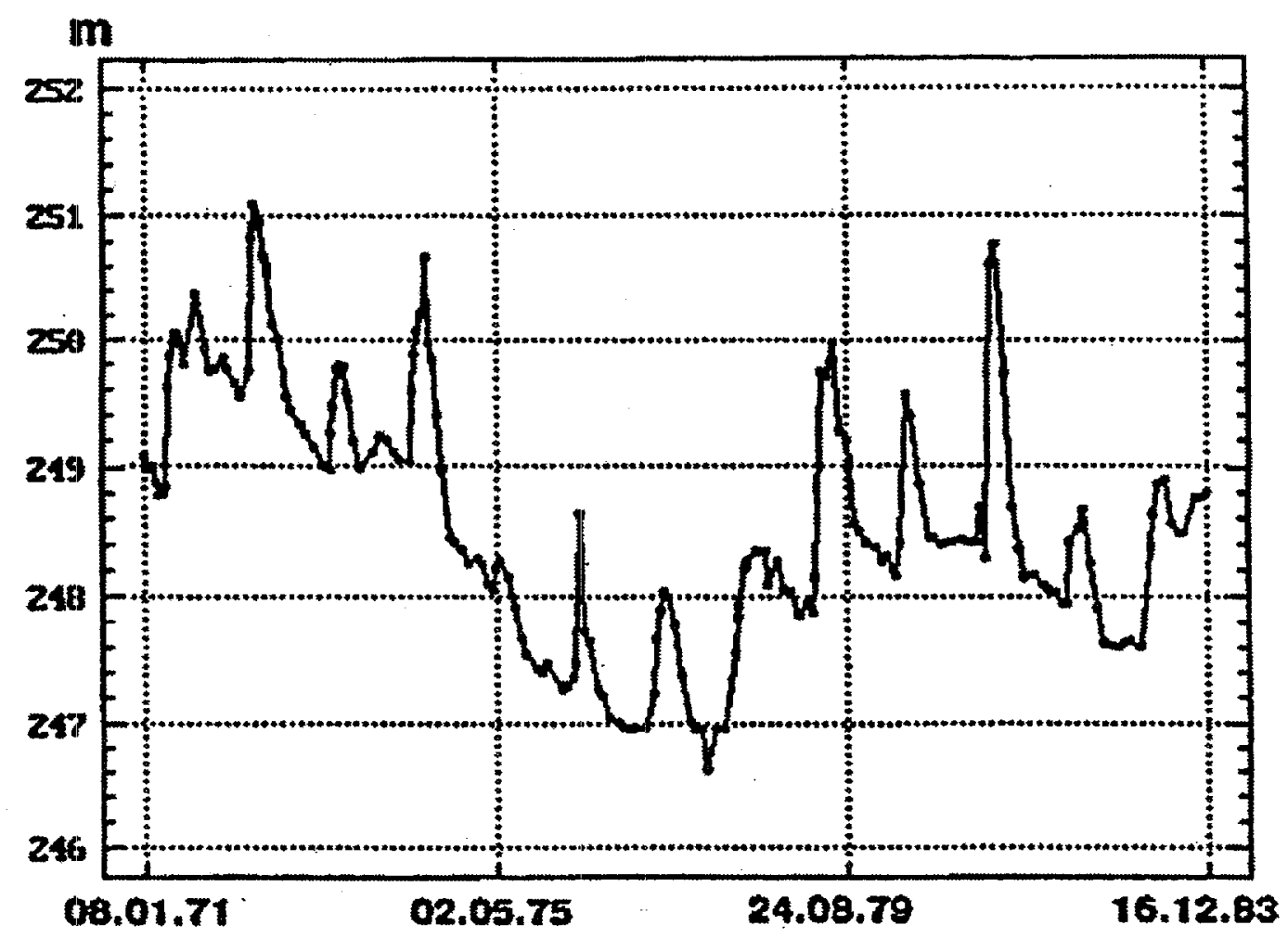

Figure 12. Water level in Well 202/68 in 1971-1983. 


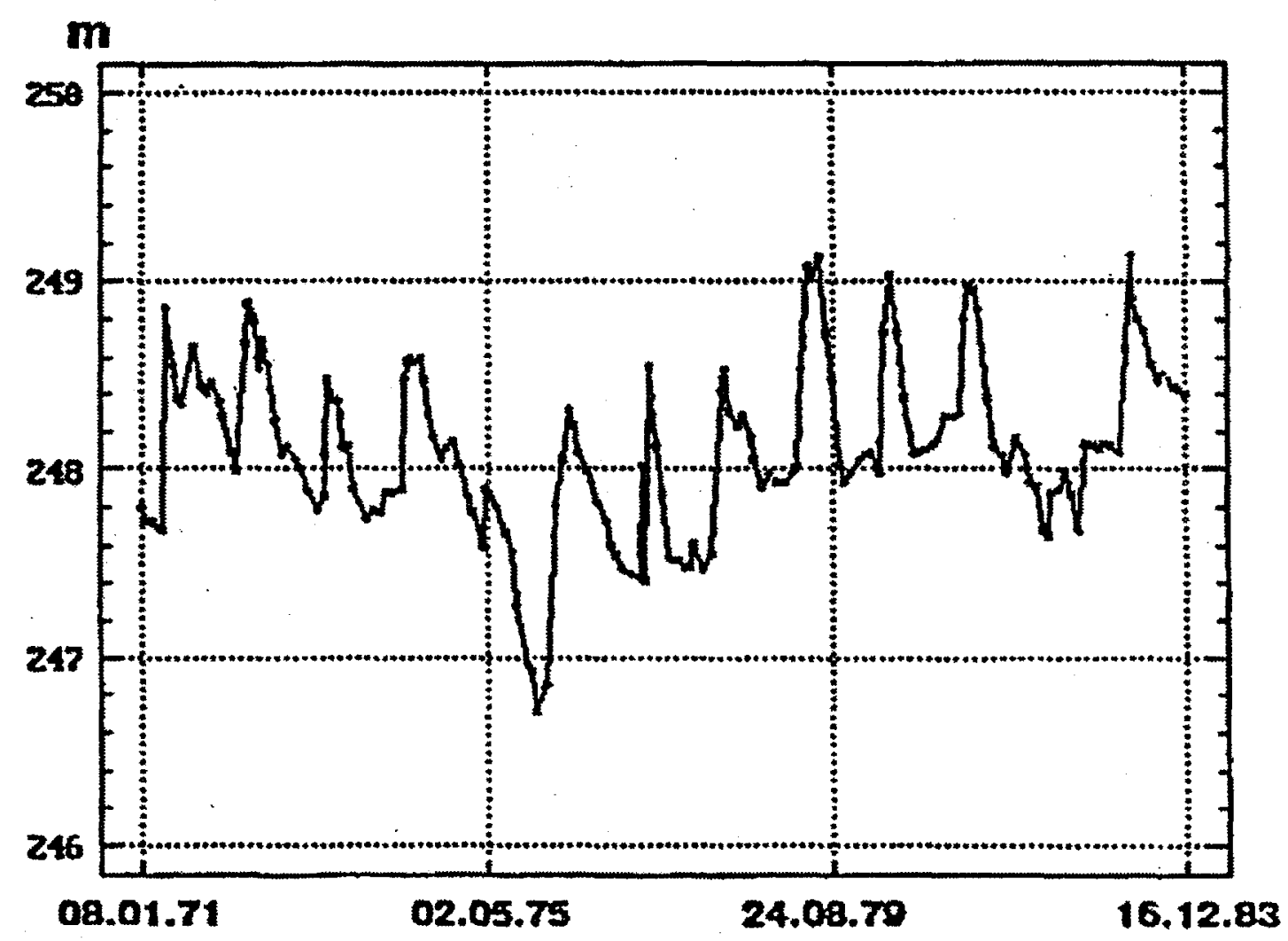

Figure 13. Water level in Well 36/70 in 1971-1983. 


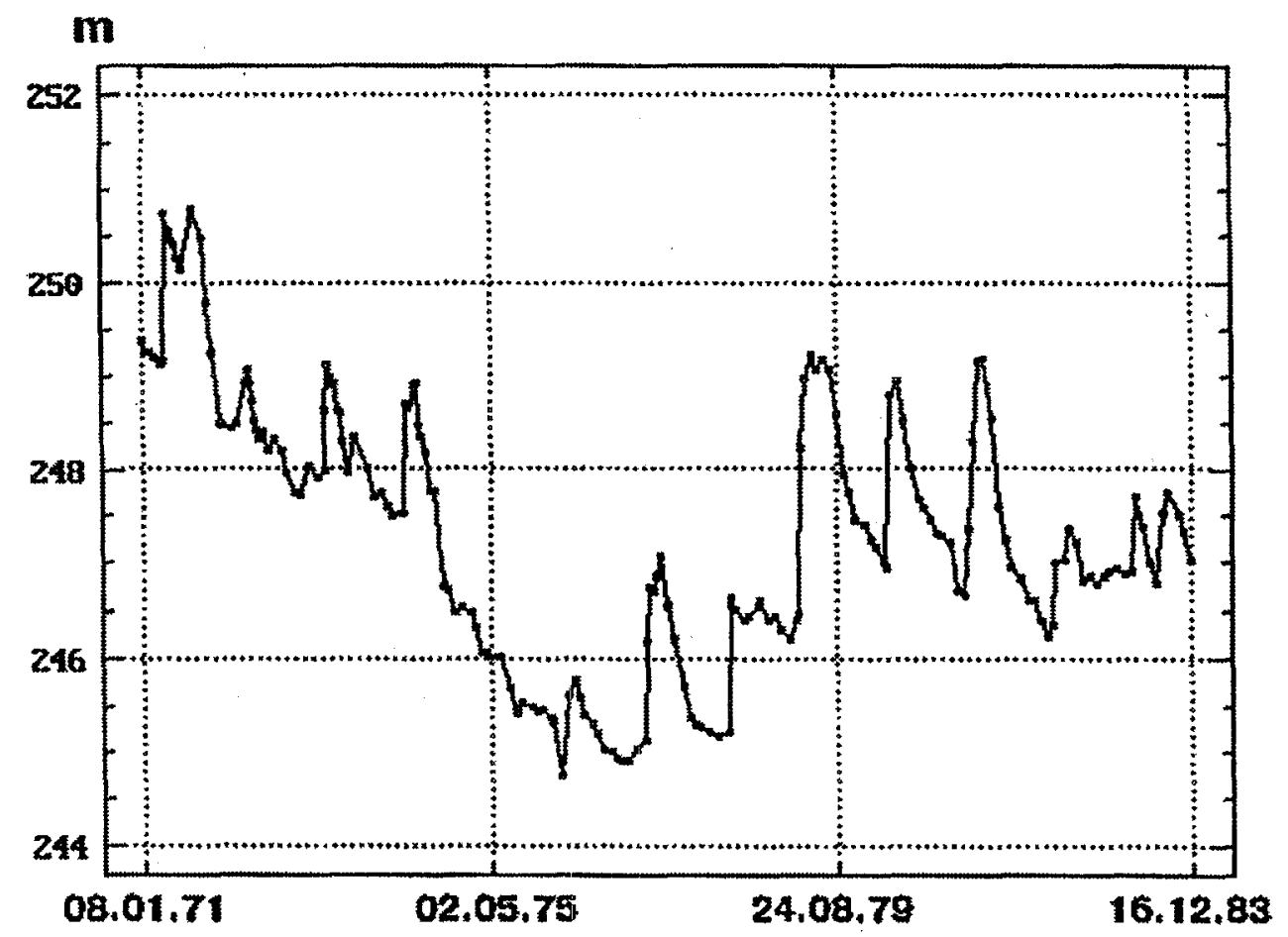

Figure 14. Water level in Well 38/70 in 1971-1983. 


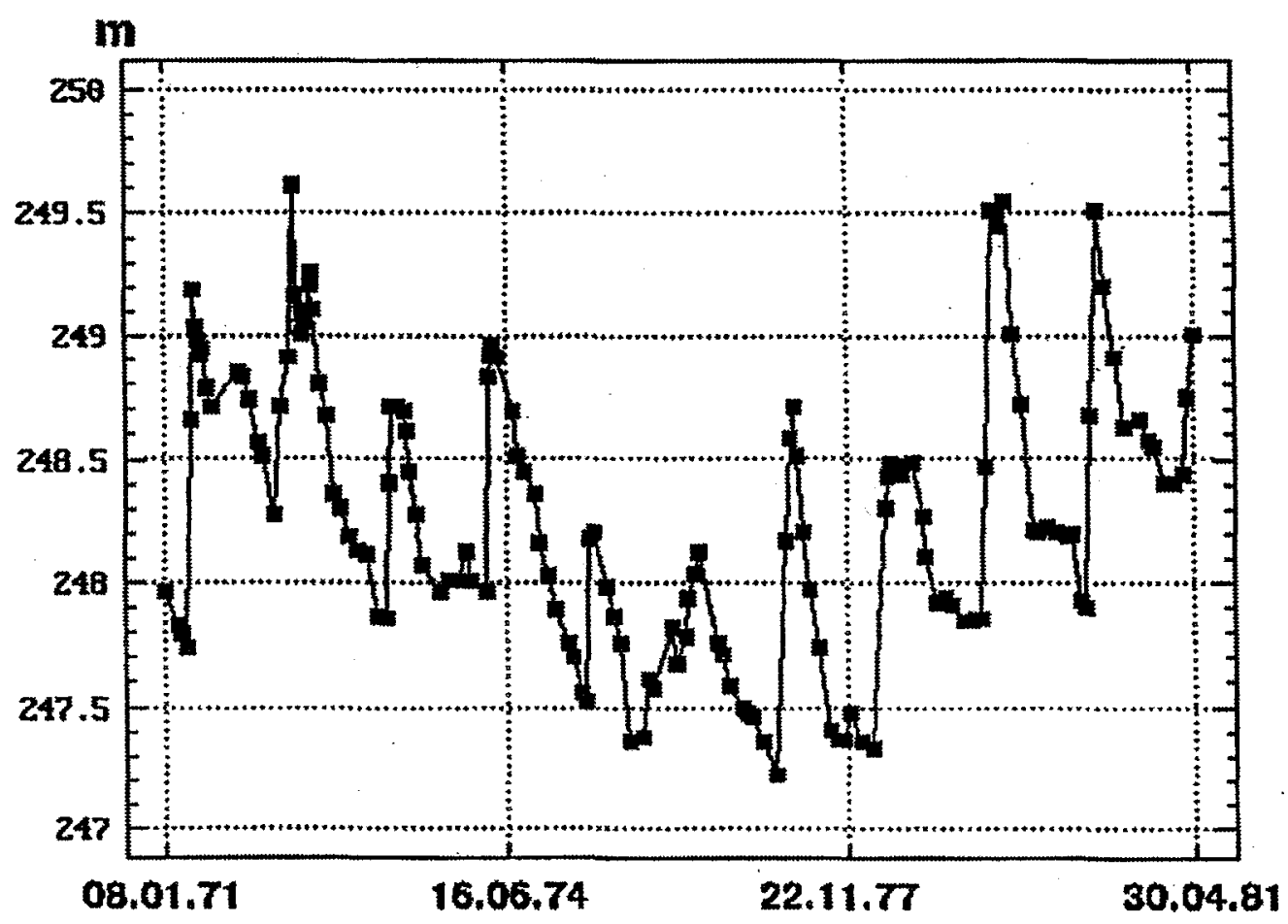

Figure 15. Water level in Well $15 / 70$ in 1971-1983. 
Figure 16. The distance from Lake Karachai to the holes.

\begin{tabular}{|c|c|c|}
\hline No. of the well & From the shore line & From the center of the lake \\
\hline $202 / 64$ & 700 & 950 South \\
\hline $10 / 68$ & 1750 & 2000 South \\
\hline $3 / 68$ & 2190 & 2440 South \\
\hline $15 / 70$ & 350 & 600 North \\
\hline $36 / 70$ & 550 & 800 North \\
\hline $38 / 70$ & 1050 & 1300 North \\
\hline
\end{tabular}

Figure 17. Lake elevations of Lakes No. 2, 3, 4, 10. Water level in the lakes, absolute elevations, m.

\begin{tabular}{|c|l|l|c|}
\hline Lakes (basin) & Maximal & Minimal & Middle (operational) \\
\hline No. 2 & 225.6 & 225 & 225.4 \\
\hline No. 3 & 223.05 & 222.7 & 223 \\
\hline No. 4 & 220.4 & 219.9 & 220.2 \\
\hline No. 10 & 218.8 & 219.84 & 219.5 \\
\hline
\end{tabular}

